\title{
Ebooks in higher education: a strategic priority?
}

\author{
Christine Fyfe
}

University of Leicester

University leaders and managers concern themselves with developments that align with institutions' strategic priorities, deliver competitive advantage, improve teaching and research performance, reduce costs and enhance value for money. Ebooks have the potential to engage with all these strategic priorities. Following the successful integration of ejournals into the academic workflow, ebooks promise much to universities aspiring to enhance students' educational experience, enrich research resources and streamline services. They have greater potential to transform the reader experience than ejournals and yet they have experienced a long and difficult birth, suffering from digital rights management, integration, discoverability and functionality challenges. It is taking much longer than expected to arrive at a position in which ebooks have a dominant and realiable part to play in students' learning and in universities' provision of texts to support both teaching and research. Indeed in the $\mathrm{UK}$, while ebook provision and use via libraries is growing rapidly (for example, the University of Leicester Library acquired 1086 ebooks in 2008/9 rising to 406,576 in 2012/13) library spending on books is still dominated by spending on print. The 2011/12 Annual Library Statistics published by the Society of College, National and University Libraries (SCONUL 2013) report that

\section{How to cite this book chapter:}

Fyfe, C. 2014. Ebooks in higher education: a strategic priority? In: Woodward, H. (ed.) Ebooks in Education: Realising the Vision. Pp. 1-7. London: Ubiquity Press. DOI: http://dx.doi.org/10.5334/bal.a 
across the 147 higher education institutions making returns total expenditure on printed books was $£ 46.4$ million and on ebooks $£ 14.8$ million.

Both the higher education sector and the publishing industry are undergoing a prolonged process of experimentation with service and provider models in a complex environment characterised by many variables and choices. As a consequence of this complexity, and of the fast pace of change, there has been insufficient time to pause and reflect on key topics such as user behaviour, the impact of the changing balance between electronic and printed books (either at individual user level, or at provider level), the rate of change towards e-only provision, and the future role of libraries.

Faced with this bewildering landscape, university leaders may easily fail to appreciate the transformative potential of ebooks to help to address a range of challenges encountered by institutions. In this chapter I attempt to explore some of the roles which ebooks may play in building successful educational institutions.

\section{Key strategic drivers}

Ebooks have the potential to engage with three key strategic priorities common to most universities: to enhance the student experience and academic outcomes within an increasingly competitive environment; to drive innovation in learning, teaching and research; and to help to use space and human resources more effectively and efficiently.

Enhancing the student experience is clearly a key strategic driver for all universities, sharpened by ever increasing global competition for well-qualified students. The abolition of student number controls in England from 2015/16 and the introduction of new private providers will drive further striving for competitive advantage between institutions. Students' (and their parents') expectations of value for money and investment in their education continue to rise within a context in which many will have a much wider choice of institution than in the past. A recent report by Moody's (2014) painted a picture of a stratified competitive environment for English higher education institutions in which responses depended on institutions' market position. Moody's described an environment in which most institutions will need to jostle for position, making strategic investments in order to attract students. League tables, which are highly influential in student choice of institution, constitute a further element of the competitive landscape. Competition clearly is not limited to student recruitment; universities also strive to improve the educational outcomes of their students in order to prepare them for employment and to reinforce institutional reputations.

Ebooks contribute to this scramble for competitive advantage by offering the exciting possibility of enhancing the student experience - what it is like to be a student - and producing better educated students. At a fundamental 
level, ebooks enhance educational benefit by improving access to titles that students are expected to read. Ensuring timely access to key books has been a fundamental, and largely intractable, challenge for universities and their libraries for many years, and lack of sufficient copies has regularly featured as the top complaint in student surveys over many years. Ebooks enable libraries to move away from inadequate and unpopular solutions to high demand for particular books, such as reliance on short-loan print collections. Making access to books more convenient, anytime, anywhere helps to meet student expectations and to assist students who are juggling the demands of study with complicated personal commitments. There remain significant challenges with institutional licensing or purchase of online textbooks in particular, but nevertheless ebooks are having a significant impact on improving student satisfaction with book provision.

There is evidence also that ebooks are not only becoming widely accepted, but also embedded in students' expectations of core provision. The University of Leicester Students' Union annual Student Voice Report for 2014 chose to ask two questions on learning resources. In answer to the question "How much of your reading is available online?" $65 \%$ of the 769 respondents indicated that most or all of their reading was available electronically. Most of this, at undergraduate level, would be books and book chapters. The second question asked "How useful would each of the following [resources] be to your learning?". Ebooks topped the list which included lecture capture, journal subscriptions, more physical books in the library and social learning space. Of the respondents, $60 \%$ deemed ebooks to be "very useful" to their learning, compared with $44 \%$ awarding physical books in the library the same judgment. It is telling that the student compilers of the survey highlighted these as the most important questions to ask, and that ebooks received strong support against other hot topics. The survey aligns with national usage statistics for ebook sections which record over 123 million requests in 2011/12 (SCONUL 2013), demonstrating that for students they have entered the mainstream.

Students increasingly resent the expectation that they should purchase books themselves, especially in the context of increased tuition fees. The National Union of Students and individual student unions have run successful campaigns to highlight what they see as hidden and unacceptable additional charges of undertaking a programme of study. Some universities, including my own, have supplied individual copies of core print books or ebooks for students which serve to enhance student satisfaction and perception of value for money. Further potential is offered by ebooks to personalise the provision of reading material to enhance the attractiveness of the offer to students.

Ebooks evidently enable universities to enhance substantially the range of titles available to students through the purchase of large packages of titles assembled by aggregators or by individual publishers. While there is inevitably some redundancy in large packages, the level of use of the popular titles and the penetration across the package will often justify the cost. As was evident 
when digital journal backsets became available, the opening up of back-list titles in electronic form boosts usage and helps to support the wider reading required for writing essays and dissertations in a much more convenient way than traditional print-based document supply. Academics at the University of Leicester confirm that they and their students read and cite more titles if the content is easily accessible.

The availability of patron- or demand-driven acquisition, in which a number of selected titles are made available to institutions, but the purchase of individual titles is triggered only when an agreed usage level has been reached, may seem to be a direct contrast with a strategy that relies on the purchase of large packages. In some institutions a more targeted approach to acquiring ebooks will be appropriate, but in others targeting can happily coexist with a range of other approaches. Both approaches are ways of maximising the chance that the reader will find and access what they want immediately, responding to an expectation of instant service. This contrasts with a considered collection building approach by libraries, highlighting a consumer focus that contributes to enhanced service and greater satisfaction.

Universities have long been involved in programmes that include professional placements, integrated work experiences or in other offerings that require students to study remotely. Students are now able to access key texts via mobile devices, and this has significantly enhanced the educational value of these activities. The educational power delivered by ebooks, of being able to access original texts from the patient's bedside, at the archaeological dig, or in the laboratory is enormous.

A further strategic benefit of ebooks is the part they can play in providing access to texts for students with disabilities. The ability to change font size, colour and contrast helps these students to have equivalent access to texts and a comparable experience to students without disabilities. In this way, ebooks support universities' widening participation agendas.

\section{Driving innovation in teaching learning and research}

The second strategic driver is innovation in teaching, learning and research. Ebooks can be embedded in online programmes or made available through virtual learning environments. The University of Leicester's MSc Security, Conflict and International Development by distance learning provides an instructive example of innovation. This programme, offered by the Department of Criminology, is aimed at those working, or intending to work, in international development. Students may be working in military environments, remote locations or as peace workers, far away from conventional study facilities. All students are provided with an iPad loaded with the course materials and relevant ebooks, and have access to a course app. Students are able to 
access material without an internet connection, which is often unavailable or unreliable in their employment environment. This is what the students say:

- I love the fact it is mobile, as I am constantly on the move. Travelling with books would be unrealistic.

- You can access all the materials without having to carry lots of books and means you can study any time any where.

- Firstly I am more motivated, as it is structured and organised. I am getting through more than I would if I was solely given a recommended reading list.

- My opinion of the course materials is very high: this is a fully immersive multimedia form of learning with core texts, videos and internet links etc presented in a clear flow. An extended bibliography gives you the option to explore the subject areas much wider.

- With the use of ebooks and the ability to download electronic academic documents from the library account, its almost paperless learning. For example, I will often be using a note taking app, ebook reader app and mindmapping app concurrently when studying while listening to music, also coming from the iPad. I only have to remember the charger!

It is striking how students respond positively not only to the accessibility of content, but also to the coherence and seamlessness offered by this approach to course design. Without ebooks, this distinctive programme would be considerably diminished, but the benefits of the approach are potentially applicable to all students. Only having to remember the charger neatly encapsulates the transformative potential of online delivery, of which an essential element is ebooks.

The rich potential offered by enhanced ebooks in terms of interactivity and multimedia is a further area for innovative design and delivery of content.

Ebooks have the power to enhance the approaches available to researchers who engage with text. The large scale digitisation of books, in addition to digitised copies of specialist collections, has made vast quantities of material discoverable and readily accessible, and has contributed to the growing importance of digital humanities. The ability to mine text (where permissible and practical) opens up new areas for enquiry and analysis, by identifying patterns across a corpus, or by highlighting features of texts that would not be discernible through traditional methods of reading.

\section{Repurposing space}

The 2011/12 SCONUL Annual Library Statistics (SCONUL 2013) record that its member libraries occupy a total of some 1.4 million square metres of space for traditional library activities, although it is not recorded what 
proportion of this space is occupied with the storage of printed books. This is an underestimate as not all libraries were able to provide the data. Commentators agree that print and ebooks will co-exist for a long time into the future, but it is evident that a continued move to ebooks will, over time, permit the reduction of prime space allocated to printed books, allowing significant quantities of space to be released for other purposes, including

formal and social learning space. This move is already underway, promising to deliver significant financial and academic benefit to institutions. It will be possible in many institutions to reduce off-site book storage space, delivering further efficiencies.

A further consideration for university managers is the extent to which access to and use of ebooks will occur outside the library service (for example through texts being provided by academic departments) or outside the institution altogether. Large-scale book digitisation projects (such as Google Books and Project Gutenberg) are obvious examples where students and researchers access material independently from the institution. The growing interest in open access ebooks from commercial publishers (for example Brill Open Books, Palgrave Open), the emergence of specialist open access publishers, and the exploration of new models provide a further dimension to the ebook landscape. Interest in open access ebooks is further evidenced by a range of high level explorations, including the current HEFCE examination of open access monographs and long-form scholarly works, the OAPEN-UK research project and the Jisc work to investigate the need for and shape of a national monographs strategy.

Universities and libraries will also wish to develop as creators and publishers of ebooks, which may form an economically viable approach to reviving university presses and enable textbook production.

\section{Closing comments}

Students and researchers experience access to book content, either whole books or sections, via personal purchase of print or ebooks, library print collections, library individual ebooks (selected by library), library individual ebooks (selected by readers through demand-driven acquisition), open access ebooks and document supply (borrowing from other libraries). Ebooks are on the cusp of becoming mainstream in learning, teaching and research. They offer significant opportunities to enhance the richness and effectiveness of education across all these areas and to deliver advantages to institutions. If we are to realise the vision, we need more research into the complexities of delivery, production and access to provide leaders with the evidence they need to influence institutional strategies. 


\section{References}

Moody's (2014) English Higher Education Reform: the strong get stronger while the rest jostle for position. Sector Comment, 17 April. https:// moodys.com

SCONUL (2013) Annual Library Statistics, 2011-12. London: SCONUL. 